\title{
Enhanced proliferation of human hepatoma cells by PAR-2 agonists via the ERK/AP-1 pathway
}

\author{
LIQUN XIE $^{1}$, YANMIN ZHENG $^{1}$, XUAN LI $^{1}$, JUNYAN ZHAO $^{1}$, XIAOYI CHEN $^{2}$, \\ $\mathrm{LI} \mathrm{CHEN}^{2}$, JING ZHOU ${ }^{1}$, OU HAI ${ }^{3}$ and $\mathrm{FEI} \mathrm{LI}^{1}$ \\ Departments of ${ }^{1}$ Gastroenterology, Affiliated Hospital, and ${ }^{2}$ Cell Biology, Logistics College of the Chinese \\ People's Armed Police Forces, Tianjin 300162; ${ }^{3}$ Department of Inner Mongolia Corps Clinic, \\ Chinese People's Armed Police Forces, Inner Mongolia 010050, P.R. China
}

Received April 16, 2012; Accepted July 13, 2012

DOI: $10.3892 / o r .2012 .2007$

\begin{abstract}
To investigate the expression and role of PAR-2 in the proliferation of the human hepatoma cell line HepG2, PAR-2 protein and mRNA expression were evaluated by immunohistochemistry, immunofluorescence and RT-PCR analysis. The signaling pathways downstream of PAR-2 activation that lead to hepatoma cell proliferation were analyzed. The results showed that PAR-2 is expressed in human hepatoma cells and PAR-2 mRNA expression was found to be upregulated in cells treated with trypsin or SLIGKV-NH ${ }_{2}(\mathrm{P}<0.001)$. The proliferation rate of HepG2 cells treated with trypsin or SLIGKV-NH $\mathrm{N}_{2}$ was significantly increased $(\mathrm{P}<0.001)$. The percentage of $\mathrm{S}$ phase, $\mathrm{G}_{2} / \mathrm{M}$ phase and the proliferation index (PI) of HepG2 cells treated with trypsin or SLIGKV-NH $\mathrm{N}_{2}$ were significantly elevated $(\mathrm{P}<0.001)$. The proliferative responses of HepG2 to trypsin and SLIGKV-NH $\mathrm{NH}_{2}$ were associated with the upregulation of c-fos and PCNA, which were significantly blocked by PD98059 pretreatment. In conclusion, our results indicate that PAR-2 enhances proliferation of human hepatoma cells possibly via the ERK/ AP-1 pathway.
\end{abstract}

\section{Introduction}

Hepatocellular carcinoma (HCC) is the most common type of human liver cancer, leading to increasing mortality rates worldwide. Currently available chemotherapies cannot achieve good prognosis for patients with unresectable HCC $(1,2)$. Therefore, it is necessary to investigate the molecular mechanisms responsible for HCC development in order to identify new targets for early diagnosis and novel treatments. Proteases have been found to be important factors in pathophysiology of tumor

Correspondence to: Dr Liqun Xie, Department of Gastroenterology, Affiliated Hospital, Medical College of Chinese People's Armed Police Forces, Tianjin 300162, P.R. China

E-mail: xieliqun66@hotmail.com

Key words: protease activated receptor-2, hepatoma carcinoma, cell proliferation, extracellular signal-regulated kinase $1 / 2$ dieases. Besides their contribution to cancer progression by degrading extracellular matrix proteins, certain proteases serve as signaling molecules through binding to specific membrane receptors, termed the protease-activated receptors (PARs). PARs are seven-transmembrane G-protein-coupled receptors, which are activated by a unique proteolytic mechanism that involves $\mathrm{N}$-terminal domain cleavage by specific serine proteases. The $\mathrm{N}$-terminal cleavage in turn generates a new tethered ligand for PARs binding and receptor activation (3). PAR-1, PAR-3 and PAR-4 are cleaved and activated by thrombin. PAR-2 is activated by trypsin and trypsin-like proteases, including some coagulation factors (4). PAR-2 can also be activated in vitro by synthetic peptides that resemble the new sequence (SLIGKV) produced after receptor cleavage (5).

Importance of trypsin, a major serine protease, has been evidenced recently in many cancers, including digestive tract tumors. Extra-pancreatic production of trypsin was found in ovarian (6), lung (7), gastric (8), and colonic tumors (9) and colon cancer cell lines as well $(10,11)$. In addition, overexpression of exogenous trypsinogen cDNA in human gastric cancer cells increases their tumorigenicity in nude mice (8).

Recently, it has been shown that trypsin targeted to PAR-2 is a very robust growth factor for human colon cancer cells (12). However, expression and functional consequences of activation of PAR-2 in hepatocellular carcinoma have not yet been reported. This study is to determine the PAR-2 expression in HepG2 cells, the effect on hepatocellular carcinoma proliferation of PAR-2 activated by trypsin or agonist peptide, and the signaling pathway molecules downstream of PAR-2 that may contribute to colon cancer cell proliferation. By using the human hepatoma cell line HepG2, we showed that upregulation of c-fos and PCNA (two downstream molecules of ERK1/2) results from activation of PAR-2 by trypsin or the synthetic activating peptide SLIGKV-NH $\mathrm{H}_{2}$. These data provide the first piece of evidence that PAR-2 is expressed in human hepatoma cells, and PAR-2 activation plays an essential role in growth of hepatoma cells, partially through the ERK/AP-1 pathway.

\section{Materials and methods}

Reagents. The PAR-2 activating peptide AP2 (SLIGKV-NH $)_{2}$ and its reverse sequence RP $\left(\mathrm{VKGILS}-\mathrm{NH}_{2}\right)$ were obtained 
from Xi'an Lianmei Biotechnology Co., Ltd. (China). Trypsin was purchased from Sigma-Aldrich (St. Louis, MO, USA). The MEK inhibitor PD98059 was purchased from Promega (USA). The goat polyclonal anti-PAR-2 antibody was purchased from Santa Cruz Biotechnology, Inc. The rabbit polyclonal anti-cfos antibody and mouse monoclonal anti-PCNA antibody were obtained from NeoMarkers for Lab Vision Corp., USA.

Cell culture. HepG2 cells were cultured in high-glucose (4.5 g/l) Dulbecco's modified Eagle's medium (DMEM) supplemented with $12 \%$ fetal calf serum (FCS, Gibco), and $100 \mu \mathrm{g} / \mathrm{ml}$ penicillin/streptomycin. The cells were incubated at $37^{\circ} \mathrm{C}, 5 \% \mathrm{CO}_{2}$ in a humidified atmosphere.

Immunocytochemical staining. The cells were fixed with cold methanol:acetone $(1: 1)$ at $-20^{\circ} \mathrm{C}$ for $10 \mathrm{~min}$, and washed three times with PBS. The fixed cells were treated with $3 \%$ hydrogen peroxide for $10 \mathrm{~min}$ to eliminate endogenous peroxidase. After blocking with rabbit serum for $10 \mathrm{~min}$, the cells were incubated with goat polyclonal antibody to PAR-2 (1:100, final dilution) for $2 \mathrm{~h}$ at $37^{\circ} \mathrm{C}$. Control cells were incubated with nonimmune goat $\operatorname{IgG} 2$, and the concentration of which was adjusted to that of the primary antibody to verify the specificity of the labeling. The cells were then incubated with biotinylated rabbit anti-goat IgG, followed by avidin peroxidase. Samples were washed and the color was developed using the Dako 3, 3-diaminobenzidine tetrahydrochloride (DAB) substrate-chromogen system. After further washes, the samples were counterstained with hematoxylin, dehydrated, and coverslipped.

Immunofluorescence staining. Immunofluorescence staining was performed on HepG2 cells grown on glass coverslips. The cells were treated with $0.2 \%$ Triton X-100 for $20 \mathrm{~min}$ at room temperature. After blocked with rabbit serum for $10 \mathrm{~min}$, the cells were incubated with goat polyclonal antibody to PAR-2 (1:100, final dilution) overnight at $4^{\circ} \mathrm{C}$. The control slides were not treated with the primary antibody. After three washes with PBS, the cells were incubated with FITC-labelled rabbit antigoat $\operatorname{IgG}\left(1: 100\right.$, final dilution) for $40 \mathrm{~min}$ at $37^{\circ} \mathrm{C}$. After three washes with PBS, confocal fluorescence images were taken with Zeiss LSM510 METANLO (Germany).

Flow cytometry. HepG 2 cells were seeded at the density of $8 \times 10^{4} /$ $\mathrm{ml}$ and allowed to attach for $24 \mathrm{~h}$. The medium was removed and the attached cells were rinsed twice with serum-free medium. The cells were replenished with serum-free medium and starved in serum-free media for $24 \mathrm{~h}$ to maintain quiescence. Then the cells were incubated with or without PAR-2 agonists $(50 \mu \mathrm{M}$ SLIGKV-NH $\mathrm{N}_{2}$ or $25 \mathrm{nM}$ trypsin) or $50 \mu \mathrm{M}$ VKGILS-NH $\mathrm{N}_{2}$. After $24 \mathrm{~h}$ of culture, the cells were harvested, washed twice with cold PBS, and fixed in $75 \%$ ethanol for at least $24 \mathrm{~h}$ at $4^{\circ} \mathrm{C}$. The cells were then washed with PBS containing $1 \%$ BSA and incubated with $100 \mu \mathrm{g} / \mathrm{ml}$ RNase A (Sigma, USA) and $50 \mu \mathrm{g} / \mathrm{ml}$ propidium iodide (Sigma) for $2 \mathrm{~h}$ at room temperature. Finally, the stained cells were analyzed on a FACSCalibur flow cytometer. Proliferation index (PI) was calculated according to the following equation: $P I=\left(S+G_{2} M\right) /\left(G_{0} G_{1}+S+G_{2} M\right) \times 100 \%$.

Reverse-transcription polymerase chain reaction (RT-PCR). To evaluate the mRNA level of PAR-2 expression in HepG2 cells,
Table I. Oligonucleotides used in this study.

\begin{tabular}{ll}
\hline Human PAR-2-F & 5'-AGAAGCCTTATTGGTAAGGTT-3' \\
Human PAR-2-R & 5'-AACATCATGACAGGTCGTGAT-3' \\
c-fos-F & 5'-AGAATCCGAAGGGAAAGGAA-3' \\
c-fos-R & 5'-CTTCTCCTTCAGCAGGTTGG-3' \\
PCNA-F & 5'-TTTCTAGGTCTCAGCCGGTC-3' \\
PCNA-R & 5'-GCAAATTCACCAGAAGGCAT-3' \\
$\beta$-actin-F & 5'-TGTTTGAGACCTTCAACACCC-3' \\
$\beta$-actin-R & 5'-AGCACTGTGTTGGCGTACAG-3' \\
\hline
\end{tabular}

and the effects of PAR-2 agonists (SLIGKV-NH $\mathrm{H}_{2}$ or trypsin) and VKGILS-NH $\mathrm{N}_{2}$ on PAR-2 expression, the culture flasks were replenished with serum-free medium and the cells were incubated for $24 \mathrm{~h}$ to maintain quiescence. Then the cells were incubated with or without PAR-2 agonists (50 $\mu \mathrm{M}$ SLIGKV-NH or $25 \mathrm{nM}$ trypsin) or $50 \mu \mathrm{M}$ VKGILS-NH$H_{2}$. After $24 \mathrm{~h}$ of culture, total RNA was extracted from the cells with TRIzol Reagent (Invitrogen Corp., Carlsbad, CA, USA). First-strand cDNA was synthesized by reverse transcription of the RNA with the Superscript Preamplification system according to the manufacturer's instructions. PCR amplification was performed with $2.5 \mathrm{U}$ of Taq DNA polymerase on $5 \mu \mathrm{g}$ of cDNA. The reaction was allowed to proceed for 35 cycles at $94^{\circ} \mathrm{C}$ for $45 \mathrm{sec}, 51^{\circ} \mathrm{C}$ for $45 \mathrm{sec}$, and $72^{\circ} \mathrm{C}$ for $90 \mathrm{sec}$. Control PCRs were performed by substituting water for cDNA and omitting RT during the DNA synthesis. To evaluate the effects of PAR-2 agonists and VKGILS- $\mathrm{NH}_{2}$ on c-fos and PCNA mRNA expression, the wells were replenished with serum-free medium and the cells were incubated for $24 \mathrm{~h}$ to maintain them quiescent. Then the cells were incubated with or without $50 \mu \mathrm{M}$ SLIGKV-NH ${ }_{2}, 25$ $\mathrm{nM}$ trypsin or $50 \mu \mathrm{M}$ VKGILS- $\mathrm{NH}_{2}$. In some experiments, HepG2 cells were preincubated for $1 \mathrm{~h}$ with $50 \mu \mathrm{M}$ PD98059 before stimulated with PAR-2 agonists. After $50 \mathrm{~min}$ and $24 \mathrm{~h}$ of culture, total RNA was extracted from the cells to detect c-fos or PCNA mRNA expression, respectively. The reaction was allowed to proceed for 35 cycles at $94^{\circ} \mathrm{C}$ for $45 \mathrm{sec}, 55^{\circ} \mathrm{C}$ for $1 \mathrm{~min}$, and $72^{\circ} \mathrm{C}$ for $45 \mathrm{sec}$. The quality of the PCR product was checked by $1.5 \%$ agarose gel electrophoresis at $90 \mathrm{~V}$ for $45 \mathrm{~min}$ and visualized by $0.5 \mu \mathrm{g} / \mathrm{ml}$ ethidium bromide. Primers used in this study are given in Table I.

Proliferation assay. HepG2 cells were seeded in 96-well culture plates at 5000 cells/well and allowed to attach for $24 \mathrm{~h}$. The medium was removed and attached cells were rinsed twice with serum-free medium. They were then grown in $100 \mu \mathrm{l}$ of culture medium without FCS for $24 \mathrm{~h}$ to maintain quiescence. Then $200 \mu \mathrm{l}$ of a fresh serum-free medium, with or without PAR-2 agonists (50 $\mu \mathrm{M}$ SLIGKV-NH ${ }_{2}$ or $25 \mathrm{nM}$ trypsin) or 50 $\mu \mathrm{M}$ VKGILS-NH $\mathrm{N}_{2}$, were added. In some experiments, HepG2 cells were preincubated for $1 \mathrm{~h}$ with $50 \mu \mathrm{M}$ PD98059 before stimulated with PAR-2 agonists. After $24 \mathrm{~h}$ of culture, cell proliferation was measured using 3-(4,5-dimethylthiazol-2-yl)2,5-diphenyl-tetrazolium bromide (MTT) (Sigma-Aldrich). Finally, the treatment medium was removed and DMSO was added to each plate, and absorbance of each well was measured at $590 \mathrm{~nm}$ using a 96-well-microplate reader. 

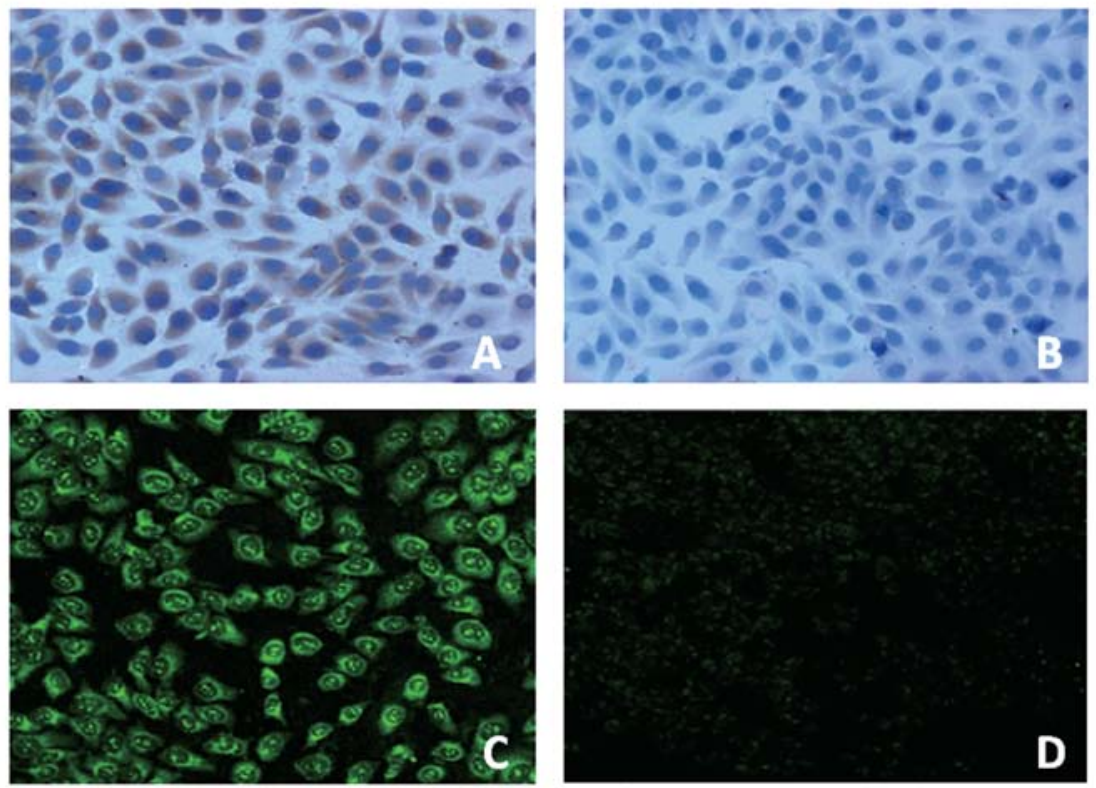

Figure 1. Expression and localization of PAR-2 in HepG2 cells. HepG2 cells were stained with goat polyclonal anti-PAR-2 antibody. Immunocytochemical staining (x200): (A) goat anti-PAR-2 antibody; (B) control antibody. Immunofluorescence staining (x200): (C) goat anti-PAR-2 antibody; (D) control antibody.

Western blot analysis. For the changes of c-fos and PCNA protein expression, HepG2 cells were grown to $50 \%$ confluence and serum-deprived for $24 \mathrm{~h}$ before the addition of PAR-2 agonists (50 $\mu \mathrm{M}$ SLIGKV-NH $\mathrm{N}_{2}$ or $25 \mathrm{nM}$ trypsin) or $50 \mu \mathrm{M}$ VKGILS-NH ${ }_{2}$. In some experiments, HepG2 cells were preincubated for $1 \mathrm{~h}$ with $50 \mu \mathrm{M}$ PD98059 before their stimulation with $50 \mu \mathrm{M}$ PAR-2 AP or $25 \mathrm{nM}$ trypsin. After 2 and $24 \mathrm{~h}$ of culture, HepG2 cells were lysed in lysis buffer containing leupeptin and phenylmethylsulfonyl fluoride to detect c-fos and PCNA protein expression, respectively. Electorophoresis was performed through a $10 \%$ sodium dodecyl sulfate (SDS) polyacrylamide gel and transferred to polyvinylidene difluoride (PVDF) membranes. Membranes were blocked in 5\% non-fat milk and washed in Tris-buffered saline (TBS) containing $0.1 \%$ Tween-20 for $1 \mathrm{~h}$ at room temperature followed by the addition of anti-c-fos or anti-PCNA antibody (1:200) overnight at $4^{\circ} \mathrm{C}$. Then, the membrane was washed with TBS/Tween-20 for $1 \mathrm{~h}$ and horseradish peroxidase-labeled anti-mouse or anti-rabbit antibody (1:5000) was used as the secondary antibody. Blots were developed with a chemiluminescence detection system (BeyoECL Plus, Beyotime Institute of Biotechnology).

Statistical analysis. Results are expressed as means \pm SD. The P-value of differences between single subgroups was calculated with the Least Significance Difference post hoc test (LSD test).

\section{Results}

PAR-2 expression in human hepatoma cell line HepG2. To confirm the expression and localization of PAR-2 at protein level, immunohistochemical and immunofluorescence analysis were carried out on human hepatoma cell line HepG2. As shown in Fig. 1, immunocytochemical and immunofluorescence staining for PAR-2 in HepG2 cells revealed its expression in the cytoplasm. No immunocytochemical or immunofluorescence signal was observed in the negative-control groups. In order to confirm whether HepG2 cells express PAR-2 at the mRNA level, we investigated the presence of specific PAR-2 mRNA transcripts in total RNA extracted from HepG2 cells. Since PAR-2 has been shown to be activated by trypsin or PAR-2-activating peptide AP2 (13), we also performed RT-PCR studies following incubation of HepG2 cells with the two activators. Fig. 2 shows that mRNA expression dramatically increased in the cells treated with trypsin or SLIGKV-NH ${ }_{2}$ compared to the control group and the reverse PAR-2 AP group $(\mathrm{P}<0.001)$, further demonstrating that PAR-2 expression has been upregulated by trypsin or PAR-2-activating peptide AP2.

Trypsin and PAR-2 AP promote HepG 2 cell growth by accelerating the hepatoma cell cycle progression. To identify the phase of cell cycle affected by trypsin, SLIGKV-NH ${ }_{2}$ or VKGILS-NH ${ }_{2}$, cell cycle distribution was assayed by flow cytometry. Cells were synchronized with 24 -h serum starvation and then induced to re-enter the cell cycle by treatment with trypsin, SLIGKV-NH ${ }_{2}$ or VKGILS-NH $\mathrm{N}_{2}$. Flow cytometric analysis was performed after propidium iodide staining. After 1-day treatment, as shown in Table II, trypsin or SLIGKV-NH treatment significantly increased the percentage of cells in the $S$ phase, $\mathrm{G}_{2} / \mathrm{M}$ phase and the proliferation index (PI) of HepG2 cells $(\mathrm{P}<0.001)$. Consequently, the percentage of cells in the $\mathrm{G}_{0} / \mathrm{G}_{1}$ phase was reduced $(\mathrm{P}<0.001)$. But there was no statistical significance of the difference between the reverse PAR-2 agonists and control group. These results suggest that trypsin or SLIGKV-NH $\mathrm{N}_{2}$ promotes cell cycle progression and stimulate the growth of HepG2 cells (Fig. 3).

Trypsin and PAR-2 AP stimulate cell proliferation in HepG2 cells via ERK phosphorylation. To evaluate the role of PAR-2 on hepatoma cell proliferation, serum-starved HepG2 cells were cultured in the presence or absence of trypsin, 

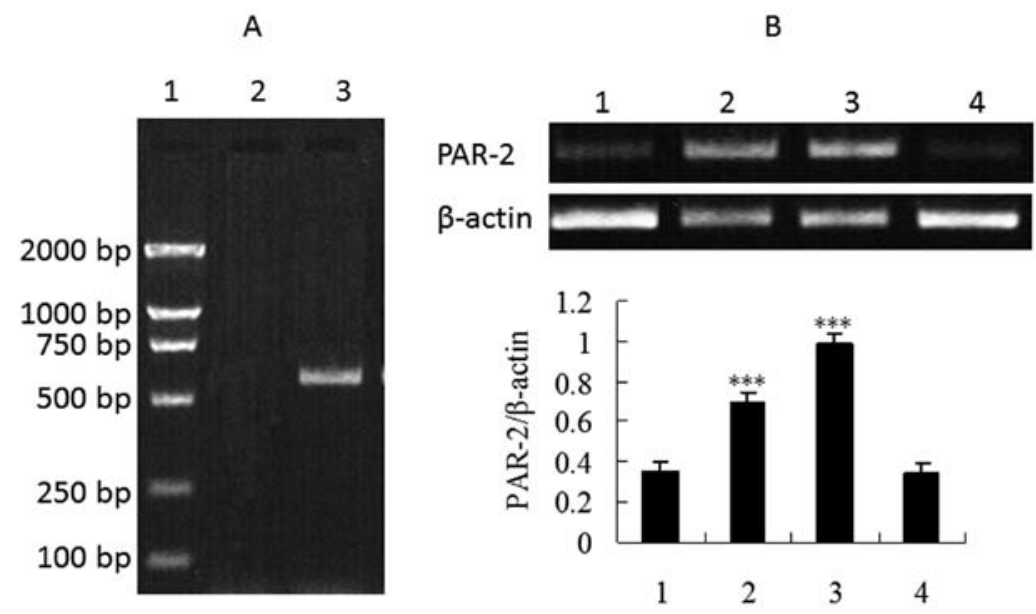

Figure 2. Detection of PAR-2 mRNA expression in HepG2 cells by RT-PCR. Total RNA extracted from HepG2 cells was reverse transcribed and amplified by PCR with PAR-2 primers. (A) Lane 1, marker. Lane 2, negative-control. Lane 3, PAR-2 expression at the mRNA level (582 bp) (B) Lane 1, control. Lane 2, SLIGKV $50 \mu \mathrm{M}$. Lane 3, trypsin $25 \mathrm{nM}$. Lane 4, VKGILS $50 \mu \mathrm{M}$. Data are expressed as means $\pm \mathrm{SD}\left({ }^{* * * *} \mathrm{P}<0.001\right.$ vs the control group).

Table II. Effects of trypsin, SLIGKV or VKGILS on cell cycle distribution in HepG2 cells.

\begin{tabular}{lcccc}
\hline & \multicolumn{4}{c}{ Cell cycle $(\%)$} \\
\cline { 2 - 5 } Group & $\mathrm{G}_{0} / \mathrm{G}_{1}$ & $\mathrm{G}_{2} / \mathrm{M}$ & $\mathrm{S}$ & PI \\
\hline Control group & $79.12 \pm 0.67$ & $9.54 \pm 0.34$ & $11.34 \pm 0.55$ & $20.88 \pm 0.67$ \\
$50 \mu$ M SLIGKV & $57.85 \pm 0.46^{\mathrm{a}}$ & $13.20 \pm 0.15^{\mathrm{a}}$ & $28.95 \pm 0.54^{\mathrm{a}}$ & $42.15 \pm 0.46^{\mathrm{a}}$ \\
$25 \mathrm{nM}$ trypsin & $56.11 \pm 0.85^{\mathrm{a}}$ & $13.49 \pm 0.44^{\mathrm{a}}$ & $30.41 \pm 0.44^{\mathrm{a}}$ & $43.88 \pm 0.86^{\mathrm{a}}$ \\
$50 \mu \mathrm{M}$ VKGILS & $79.27 \pm 0.85$ & $9.51 \pm 0.47$ & $11.23 \pm 0.54$ & $20.73 \pm 0.85$ \\
\hline
\end{tabular}

a Dfferent from control, $\mathrm{P}<0.001$.

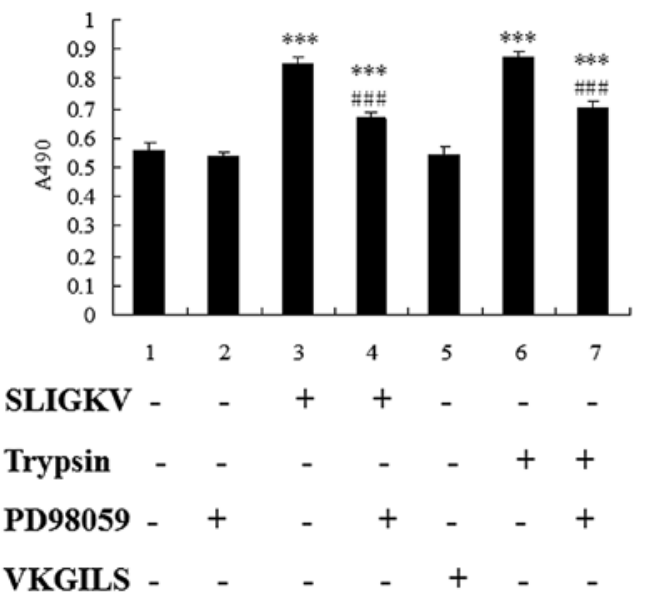

Figure 3. Trypsin or SLIGKV-NH 2 stimulates HepG2 cell growth and MEK inhibitor PD98059 inhibits PAR-2 agonist-induced cell proliferation. Cells grown in serum-free medium were stimulated with or without trypsin $(25 \mathrm{nM})$, SLIGKV $(50 \mu \mathrm{M})$, or VKGILS $(50 \mu \mathrm{M})$ in the absence or presence of PD98059. Data are expressed as means $\pm \mathrm{SD}\left({ }^{* * *} \mathrm{P}<0.001\right.$ vs the control group. ${ }^{\# \# \#} \mathrm{P}<0.001$ vs the former group).

SLIGKV-NH $\mathrm{N}_{2}$ or VKGILS- $\mathrm{NH}_{2}$, and the proliferation rate of HepG2 cells was evaluated after $24 \mathrm{~h}$ of culture. In some experiments, HepG2 cells were preincubated for $1 \mathrm{~h}$ with 50 $\mu \mathrm{M}$ PD98059 before cell stimulation with PAR-2 agonists. Because ERK1/2 has been shown to play a pivotal role in the pathway leading to growth factor-regulated proliferation (14), we used the pharmacological inhibitor PD98059 to determine the involvement of ERK1/2 in the growthstimulating effect of PAR-2. The results from MTT assays showed that, the proliferation rate of HepG2 cells treated with trypsin or SLIGKV-NH $\mathrm{N}_{2}$ was significantly increased $(\mathrm{P}<0.001)$, and pretreatment of HepG2 cells with PD98059 resulted in significant decrease of cell proliferation induced by SLIGKV or trypsin $(\mathrm{P}<0.001)$. There was no statistical significance of the difference between VKGILS and control group. These data clearly show that PAR-2 agonists act as growth factors for HepG2 cells through the MEK/ERK1/2 pathway.

Blockade of ERK1/2 phosphorylation inhibits PAR-2 mediated enhancement of transcription and protein expression of c-fos in Hep 2 cells. Because PAR-2-mediated HepG2 cell proliferation could be influenced by inhibitor of MEK, we sought to identify whether PD98059 inhibits PAR-2-mediated enhancement of transcription and protein expression of the immediate-early gene c-fos in HepG2 cells. As shown in Fig. 4, the mRNA and protein expression of c-fos were 
A

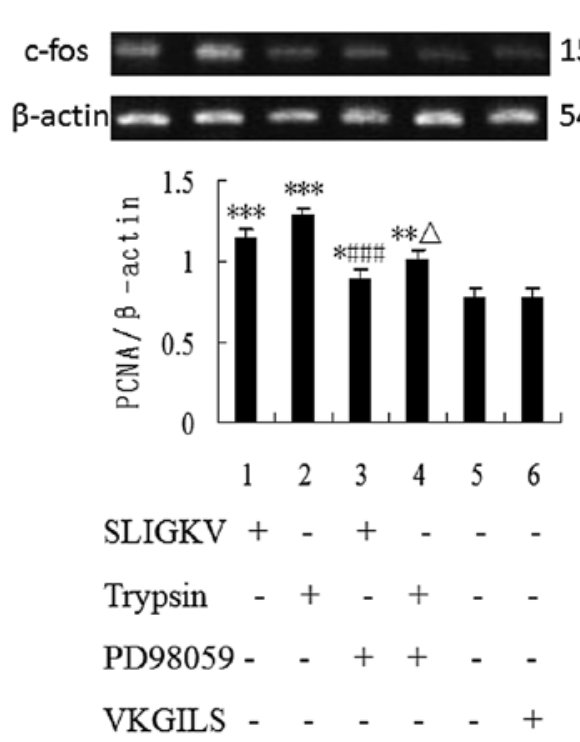

B

$50 \mathrm{bp} \quad \mathrm{c}-\mathrm{fos}$

540 bp $\beta$-actin

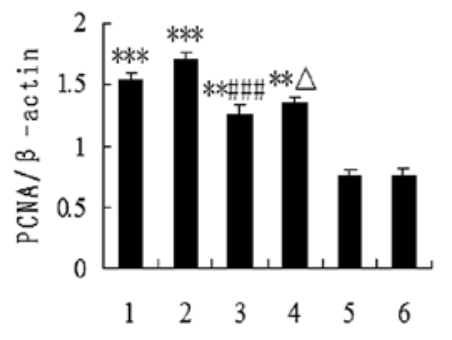

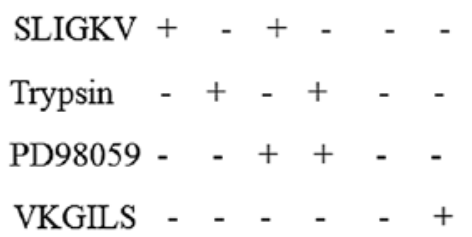

Figure 4. PD98059 inhibits the upregulation of c-fos transcription and protein expression by. Cells grown in serum-free medium were stimulated without or with trypsin $(25 \mathrm{nM})$, SLIGKV $(50 \mu \mathrm{M})$, or VKGILS $(50 \mu \mathrm{M})$ in the absence or presence of PD98059 (50 $\mu \mathrm{M})$. (A) c-fos mRNA expression in HepG2 cells treated with trypsin, SLIGKV, or VKGILS in the absence or presence of PD98059. (B) c-fos protein expression in HepG2 cells treated with trypsin, SLIGKV, or VKGILS in the absence or presence of PD98059. Data are expressed as the means $\pm \mathrm{SD}\left(\mathrm{n}=3,{ }^{* *} \mathrm{P}<0.01\right.$ vs the control group; ${ }^{* * *} \mathrm{P}<0.001$ vs the control group; ${ }^{\# \# \#} \mathrm{P}<0.001$ vs SLIGKV group; $\mathrm{P}<0.001$ vs trypsin group).

A
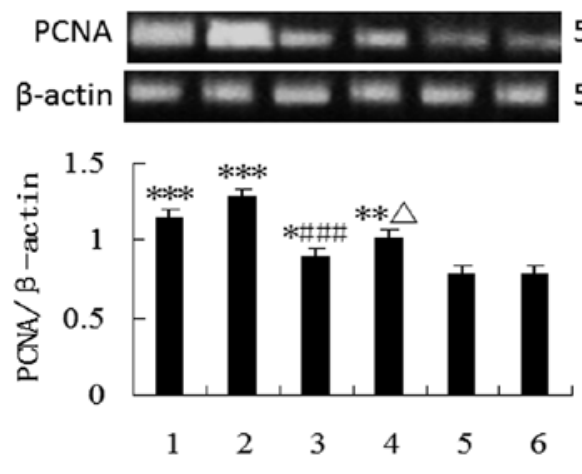

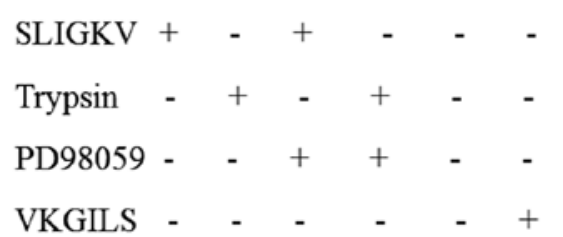

B
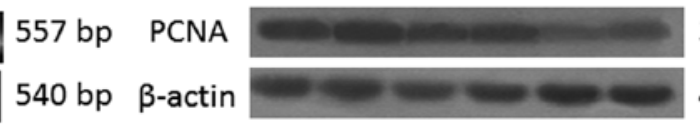

$36 \mathrm{kDa}$

$45 \mathrm{kDa}$

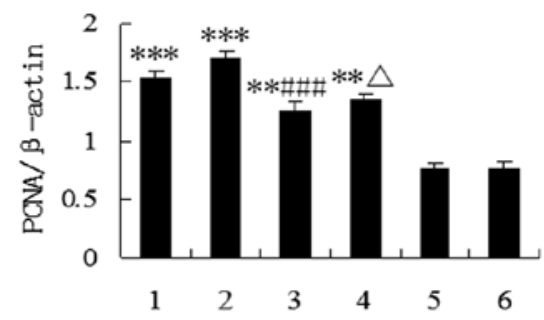

$\begin{array}{lllllll}\text { SLIGKV } & + & - & + & - & - & - \\ \text { Trypsin } & - & + & - & + & - & - \\ \text { PD98059 } & - & - & + & + & - & - \\ \text { VKGILS } & - & - & - & - & - & +\end{array}$

Figure 5. PD98059 inhibits the upregulation of PCNA mRNA and protein expression. Cells grown in serum-free medium were stimulated without or with trypsin $(25 \mathrm{nM})$, SLIGKV $(50 \mu \mathrm{M})$, or VKGILS $(50 \mu \mathrm{M})$ in the absence or presence of PD98059. (A) PCNA mRNA expression in HepG2 cells treated with trypsin, SLIGKV, or VKGILS in the absence or presence of PD98059. (B) PCNA protein expression in HepG2 cells treated with trypsin, SLIGKV, or VKGILS in the absence or presence of PD98059. Data are expressed as the means $\pm \mathrm{SD}\left(\mathrm{n}=3 ;{ }^{*} \mathrm{P}<0.05\right.$ vs the control group; ${ }^{* *} \mathrm{P}<0.01$ vs the control group; ${ }^{* * *} \mathrm{P}<0.001$ vs the control group; ${ }^{\# \#} \mathrm{P}<0.001$ vs $\mathrm{SLIGKV}$ group; $\mathrm{P}<0.001$ vs trypsin group).

upregulated in HepG2 cells stimulated by PAR-2 agonists $(50 \mu \mathrm{M}$ SLIGKV-NH 2 or $25 \mathrm{nM}$ trypsin) $(\mathrm{P}<0.001)$ and the upregulation of c-fos by PAR-2 activators was significantly blocked by PD98059 $(\mathrm{P}<0.001)$. There was no statistical significance of the difference between VKGILS and control group. Densitometric analyses showed significant differences for each of the experiments.
PD98059 inhibits PAR-2 agonist-induced PCNA mRNA and protein upregulation. As shown by RT-PCR and western blot analysis (Fig. 5), the mRNA and protein expression of PCNA were unregulated in HepG2 cells stimulated by PAR-2 agonists (50 $\mu \mathrm{M}$ SLIGKV-NH$H_{2}$ or $25 \mathrm{nM}$ trypsin), $24 \mathrm{~h}$ of treatment $(\mathrm{P}<0.001)$. Furthermore, the upregulation of PCNA expression induced by PAR-2 activators in HepG2 cells was significantly 
blocked by pretreatment with the inhibitor PD98059 ( $\mathrm{P}<0.001)$. In contrast, no change of PCNA expression was observed in HepG2 cells with VKGILS-NH ${ }_{2}$ treatment.

\section{Discussion}

Tumor micro-environment is rich in active molecules such as growth factors, inflammatory mediators, cytokines and proteinases (e.g. metalloproteases and serine proteases). Proteolytic enzymes regulate the proliferation, angiogenesis, invasion and metastasis in cells (15). Trypsin not only degrades extracellular matrix proteins but also modulates cellular functions through PAR-2 activation (16). New insights into tumor biology research have revealed a key role of trypsin in stomach, colorectal and pancreatic tumor progression (17). Recently, it has been shown that downregulation of trypsin (11) or serine protease inhibitors suppress carcinogenesis in many in vivo and in vitro assays (18). Thus, we speculate that trypsin, and possibly other serine proteases targeting PAR-2, can be used as new important signaling proteins in the control of HCC growth.

In this study, the expression of PAR-2 and role of PAR-2 in human hepatoma cell line were reported for the first time. The human hepatoma cell line HepG2 was used as a model cell line and our result showed that PAR-2 was expressed mainly in cell membrane and cytoplasm. RT-PCR studies showed PAR-2 mRNA was expressed in HepG2 cells, and the mRNA expression dramatically increased in the cells treated with trypsin or SLIGKV-NH $\mathrm{N}_{2}$ compared to the control group or the reverse PAR-2 AP treated group. The upregulation of PAR-2 mRNA may be due to the appearance of desensitization and hydrolization induced by PAR-2 activation, resulting in the feedback upregulation of PAR-2 mRNA. PAR-2 activation by trypsin plays a key role in hepatoma cells and we found activation of PAR-2 in hepatoma cells by a specific, synthetic, peptide SLIGKV resulted in enhancement of cell proliferation, mimicking the trypsin effect. In contrast, the reverse peptide was devoid of any mitogenic effect. Based on the above, it is conceivable that the use of selective and potent PAR-2 antiagonists or trypsin inhibitors may be useful for HCC treatment. As previously reported by others (19), compared to trypsin, AP2 is an agonist with lower potency. The differences in the potency of AP2 are probably due to the nonsufficient presentation of AP2 to the binding domain of PAR-2. To clarify the role of PAR-2 activation by trypsin or PAR-2 AP in HepG2 cell cycle progression, the percentage of $G_{1}$ phase, $S$ phase, $\mathrm{G}_{2} / \mathrm{M}$ phase and proliferation index (PI) of HepG2 cells were investigated. We found that trypsin and SLIGKV-NH significantly reduced the ratio of $\mathrm{G}_{0} / \mathrm{G}_{1}$ phase, but increased the percentage of $S$ phase, $G_{2} / M$ phase and proliferation index (PI) in HepG2 cells, compared to the control group and VKGILS-NH group. These data suggest that PAR-2 agonists accelerate the progress of cell cycle from $G_{0} / G_{1}$-phase to $S$ and $G_{2} / M$ phase, and promote the synthesis of DNA of hepatoma cells. Previous studies by others have demonstrated that cyclin D1 promoted the $\mathrm{G}_{1}-\mathrm{S}$ phase of the cell cycle and was frequently overexpressed in many human cancers including HCC $(20,21)$, and downregulation of cyclin D1 inhibited HCC growth in animal models (22). Therefore, we speculate that one mechanism by which PAR-2 activation induced HCC proliferation is through the control of cyclin D1 expression. Further research is ongoing to demonstrate this phenomenon.
The efficient and potent mitogenic action of trypsin on hepatoma cells raises the question of the endogenous source(s) of trypsin or other serine proteases that can activate PAR-2 in situ in HCC. The importance of locally secreted trypsin at the vicity of HCC should be emphasized: i) normal epithelia cells surrounding hepatoma cells are likely a source of active trypsin (23); ii) blood vessels surrounding tumors also express trypsin (24); iii) it has been suggested from studies in pancreas that trypsin-like enzymes secreted by tumor cells could directly regulate growth of pancreatic cells in an autocrine manner by interacting with PAR-2 (20). In gastric carcinoma cells, it has recently been reported that trypsinogen secreted by tumor cells, when activated to trypsin, can stimulate the growth and adhesiveness of the producer cells in an autocrine manner (25). Thus, we speculate that some hepatoma cell lines may produce and secrete trypsinogens as well (4). Trypsin is also present in serum at nanomolar concentrations and can diffuse from blood to tumor cells. Elevated trypsin levels were reported in the serum of patients with HCC (26), suggesting that serum may be an important source of trypsin in cancer patients. These data suggest the possibility of autocrine/paracrine regulation of PAR-2 activity by trypsin in hepatoma cells.

To elucidate the mechanism by which PAR-2 induces hepatoma cell proliferation, the cell signaling pathway leading to cell proliferation after activaton of PAR-2 was analyzed. PAR-mediated signaling is known to be involved in the activation of MAPK cascades in a number of cells (27). The extracellular signal-regulated kinase 1/2 (ERK1/2) pathway typically transduces growth factor signals that lead to cell differentiation or proliferation. Our data demonstrated that the MEK (upstream activator of ERK1/2) inhibitor PD98059 strongly decreased hepatoma cell proliferation stimulated by PAR-2 agonists. Thus, the relationship between ERK1/2 and cell proliferation is well demonstrated. Although the intracellular pathways responsible for PAR-2-mediated stimulation of ERK1/2 phosphorylation by PAR-2 agonists needs further research, it is worth mentioning that PAR-2 agonists transactivate the EGF-R through a pathway that includes matrix metalloproteinase-dependent cleavage and release of TGF- $\alpha$, which in turn activates the EGF-R and downstream MAPK cascade, leading to cell proliferation (28). Moreover, PAR-2 couples Gaq/11 and phospholipase $C \beta$, leading to hydrolysis of phosphatidylinositol bisphosphate, $\mathrm{Ca}^{2+}$ mobilization, and activation of protein kinase $\mathrm{C}$ (PKC) and ERK1/2 (29). These data suggest that PAR-2 agonists may stimulate the proliferation of hepatoma cells by EGFR-ERK1/2 or $\mathrm{Ca}^{2+}$-ERK1/2 pathway.

The activator protein-1 (AP-1) transcription factor is a family of transcription factors composed of homodimers and heterodimers which are members of Jun, Fos, and ATF subfamilies that bind to a common DNA site, the AP-1 binding site (30). MAPKs are upstream activators of AP-1 (31). ERK, p38, and JNK, subfamilies of the MAPK pathway, induce Fos and Jun production by activating different transcription factors such as Elk-1 and ATF. It has been demonstrated that AP-1 plays a central role in tumorigenesis (32). ERK1/2 pathway is responsible for the phosphorylation and activation of AP-1 protein. Fos protein differ significantly in both of their DNA binding sites and trans-activation potential as well as their target gene regulation. Overexpression of c-fos 
can efficiently transform cells and lead to tumor formation Proliferating cell nuclear antigen (PCNA) is a $36-\mathrm{kDa}$ nuclear marker of cell proliferation since its expression and distribution are correlated with the rate of cell proliferation and DNA synthesis in various tumors (33). PCNA is an auxiliary protein of DNA polymerase- $\delta$ that functions during the cell cycle (34). The distribution of PCNA increases during $G_{1}$ phase, peaks at the $G_{1} S$ interphase and decreases during $G_{2}$ phase (35). The PCNA gene contains AP-1 sites in promoter region and its expression is regulated by AP-1 activity (36). In this study, we have shown significant upregulation of c-fos and PCNA in response to trypsin or PAR-2 AP, and the effect was strongly decreased by PD98059. The results suggest that PAR-2 agonists may elevate the rate of cell proliferation and DNA synthesis in hepatoma cells by ERK1/2-AP-1 pathway. Additional studies are needed to explore other transcription factors and their target genes in the progression of hepatoma induced by activation of PAR-2. Previous studies have demonstrated that the activation of PAR-2 stimulated proliferation of ESC through $\mathrm{p} 38^{\mathrm{MAPK}}$, p42/44 $4^{\mathrm{MAPK}}$, and SAPK/JNK pathways (37). It has also been demonstrated that nuclear factor kappa $\mathrm{B}(\mathrm{NF}-\kappa \mathrm{B})$ signaling mediated by PAR-2 is regulated by intracellular $\mathrm{Ca}^{2+}$ in skin epithelial cell line NCTC2544, independent of ERK and $\mathrm{p} 38^{\mathrm{MAPK}}$ pathways (38). NF- $\kappa \mathrm{B}$ transcription factors play a key role in many physiological processes such as cell proliferation, cell death, and inflammation (39). Thus, we speculate that the proliferation of HepG2 induced by PAR-2 agonists may also be related to other pathways, such as the $\mathrm{p} 38^{\mathrm{MAPK}}, \mathrm{SAPK} / \mathrm{JNK}$, $\mathrm{Ca}^{2+} / \mathrm{NF}-\kappa \mathrm{B}$ pathways.

In conclusion, our data demonstrated that PAR-2 played an important role in proliferation of hepatoma cells, and PAR-2 activation promoted the proliferation of hepatoma cells partially via the ERK/AP-1 pathway. Further studies are needed to clarify other mechanisms of PAR-2-induced signaling pathways leading to hepatoma cell proliferation.

\section{Acknowledgements}

We thank instructor Zhong-wei Xu and Xia Mai (Department of Cell Biology, Logistics College of the Chinese People's Armed Police Forces) for assistance with western blotting technique; Dr Yu-xian Yan and instructor Jing-tian Han (Centralab, Logistics College of the Chinese People's Armed Police Forces) for help with immunocytochemical and immunofluorescence analysis; and Dr Xue-jun Cui (Department of English, Medical College of the Chinese People's Armed Police Forces) for careful revision of the manuscript.

\section{References}

1. Bosch FX, Ribes J, Díaz M and Cléries R: Primary liver cancer: worldwide incidence and trends. Gastroenterology 127: S5-S16, 2004.

2. Bruix J, Boix L, Sala M and Llovet J: Focus on hepatocellular carcinoma. Cancer Cell 5: 215-219, 2004.

3. Hollenberg MD and Compton SJ: International Union of Pharmacology. XXVIII: protease-activated receptors. Pharmacol Rev 54: 203-219, 2002.

4. Uusitalo-Jarvinen H, Kurokawa T, Mueller BM, AndradeGordon P, Friedlander M and Ruf W: Role of protease activated receptor 1 and 2 signaling in hypoxia induced angiogenesis arterioscler. Thromb Vasc Biol 27: 1456-1462, 2007.
5. Kirkland JG, Cottrell GS, Bunnett NW and Corvera CU: Agonists of protease-activated receptors 1 and 2 stimulate electrolyte secretion from mouse gallbladder. Am J Physiol Gastrointest Liver Physiol 293: 335-346, 2007.

6. Hirahara F, Miyagi Y, Miyagi E, et al: Trypsinogen expression in human ovarian carcinomas. Int J Cancer 63: 176-181, 1995

7. Kawano N, Osawa H, Ito T, et al: Expression of gelatinase A, tissue inhibitor of metalloproteinases-2, matrilysin, and trypsin (ogen) in lung neoplasms: an immunohistochemical study. Hum Pathol 28: 613-622, 1997.

8. Miyata S, Miyagi Y, Koshikawa N, et al: Stimulation of cellular growth and adhesion to fibronectin and vitronectin in culture and tumorigenicity in nude mice by overexpression of trypsinogen in human gastric cancer cells. Clin Exp Metastasis 16: 613-622, 1998.

9. Williams SJ, Gotley DC and Antalis TM: Human trypsinogen in colorectal cancer. Int J Cancer 93: 67-73, 2001.

10. Miyata S, Koshikawa N, Higashi S, et al: Expression of trypsin in human cancer cell lines and cancer tissues and its tight binding tosoluble form of Alzheimer amyloidprecursor protein in culture. J Biochem 125: 1067-1076, 1999.

11. Bernard-Perrone F, Carrere J, Renaud W, et al: Pancreatic trypsinogen I expression during cell growth and differentiation of two human colon carcinoma cells. Am J Physiol 274: G1077-G1086, 1998.

12. Darmoul D, Marie JC, Devaud H, Gratio V and Laburthe M: Initiation of human colon cancer cell proliferation by trypsin acting at protease-activated receptor-2. Br J Cancer 85: 772-779, 2001.

13. Hansen KK, Oikonomopoulou K, Li Y and Hollenberg MD: Proteinases, proteinase-activated receptors (PARs) and the pathophysiology of cancer and diseases of the cardiovascular, musculoskeletal, nervous and gastrointestinal systems. Naunyn Schmiedebergs Arch Pharmacol 377: 377-392, 2008.

14. McCubrey JA, Steelman LS, Chappell WH, et al: Roles of the Raf/MEK/ERK pathway in cell growth, malignant transformation and drug resistance. Biochim Biophys Acta 1773: 1263-1284, 2007.

15. van Kempen LC, de Visser KE and Coussens LM: Inflammation, proteases and cancer. Eur J Cancer 42: 728-734, 2006.

16. Sánchez-Hernández PE, Ramirez-Dueñas MG, AlbarranSomoza B, García-Iglesias T, del Toro-Arreola A, Franco-Topete R and Daneri-Navarro A: Protease-activated receptor-2 (PAR-2) in cervical cancer proliferation. Gynecol Oncol 108: 19-26, 2008.

17. Nyberg P, Ylipalosaari M, Sorsa T and Salo T: Trypsins and their role in carcinoma growth. Exp Cell Res 312: 1219-1228, 2006.

18. Kennedy AR, Billings PC, Wan XS and Newberne PM: Effects of Bowman-Birk Inhibitor on Rat Colon Carcinogenesis. Nutr Cancer 43: 174-186, 2002.

19. Vergnolle N: Proteinase-activated receptors - novel signals for gastrointestinal pathophysiology. Aliment Pharmacol Ther 14: 257-266, 2000.

20. O'Brien PJ, Molino M, Kahn M and Brass LF: Protease activated receptors: theme and variations. Oncogene 20: 1570-1581, 2001.

21. Masaki T, Shiratori Y, Rengifo W, et al: Cyclins and cyclindependent kinases: comparative study of hepatocellular carcinoma versus cirrhosis. Hepatology 37: 534-543, 2003.

22. Uto H, Ido A, Moriuchi A, et al: Transduction of antisense cyclin Dlusing two-step gene transfer inhibits the growth of rat hepatoma cells. Cancer Res 61: 4779-4783, 2001.

23. Koshikawa N, Hasegawa S, Nagashima Y, et al: Expression of trypsin by epithelial cells of various tissues, leukocytes, and neurons in human and mouse. Am J Pathol 153: 937-944, 1998.

24. Koshikawa N, Nagashima Y, Miyagi Y, Mizushima H, Yanoma S, Yasumitsu $\mathrm{H}$ and Miyazaki K: Expression of trypsin in vascular endothelial cells. FEBS Lett 409: 442-448, 1997.

25. Miyata S, Koshikawa N, Yasumitsu H and Miyazaki KJ: Trypsin stimulates integrin $\alpha(5) \beta(1)$-dependent adhesion to fibronectin and proliferation of human gastric carcinoma cells through activation of proteinaseactivated receptor-2. J Biol Chem 275: 4592-4598, 2000.

26. Hendstrom J, Haglund C, Haapiainen C and Stenman UH: Serum trypsinogen-2 and trypsin-2- $\alpha 1$-antitrypsin complex in malignant and benign digestive-tract disease. Preferential elevation in patients with cholangiocarcinoma. Int J Cancer 66: 326-331, 1996.

27. Sabri A, Guo J, Elouardighi H, Darrow AL, Andrade-Gordon P and Steinberg SF: Mechanisms of protease-activated receptor-4 actions in cardiomyocytes. Role of Src tyrosine kinase. J Biol Chem 278: 11714-11720, 2003. 
28. Caruso R, Pallone F, Fina D, et al: Protease-activated receptor-2 activation in gastric cancer cells promotes epidermal growth factor receptor trans-activation and proliferation. Am J Pathol 169: 268-278, 2006.

29. Ossovskaya VS and Bunnett NW: Protease-activated receptors: contribution to physiology and disease. Physiol Rev 84: 579-621, 2004.

30. Whitmarsh AJ and Davis RJ: Transcription factor AP-1 regulation by mitogen-activated protein kinase signal transduction pathway. J Mol Med 74: 589-607, 1996.

31. Karin M, Liu Z and Zandi E: AP-1 function and regulation. Curr Opin Biol 9: 240-246, 1997.

32. Sun Y and Oberley LW: Redox regulation of transcriptional activators. Free Radic Biol Med 21: 335-348, 1996.

33. Yu CC and Filipe MI: Update on proliferation-associated antibodies applicable to formalin-fixed paraffinembedded tissue and their clinical apprications. Histochem J 25: 843-853, 1993.

34. Williams GJ, Johnson K, Rudolf J, et al: Structure of the heterotrimeric PCNA from Sulfolobus solfataricus. Acta Crystallograph Sect F Struct Biol Cryst Commun 62: 944-948, 2006.
35. Sourisseau T, Georgiadis A, Tsapara S, Ali R, Pestell R, Matter K and Balda MS: Regulation of PCNA and cyclin D1 expression and epithelial morphogenesis by the ZO-1-regulated transcription factor ZONAB/DbpA. Mol Cell Biol 26: 2387-2398, 2006.

36. Gillardon F, Moll I and Uhlmann E: Inhibition of c-Fos expression in the UV-irradiated epidermis by topical application of antisense oligodeoxynucleotides suppresses activation of proliferating cell nuclear antigen. Carcinogenesis 16: 1853-1856, 1995.

37. Hirota Y, Osuga Y, Hirata T, et al: Activation of proteaseactivated receptor 2 stimulates proliferation and interleukin (IL)-6 and IL-8 secretion of endometriotic stromal cells. Hum Reprod 20: 3547-3553, 2005.

38. Macfarlane SR, Sloss CM, Cameron P, Kanke T, McKenzie RC and Plevin R: The role of intracellular $\mathrm{Ca}^{2+}$ in the regulation of proteinase-activated receptor-2 mediated nuclear factor kappa $\mathrm{B}$ signalling in keratinocytes. Br J Pharmacol 45: 535-544, 2005.

39. Baud V and Karin M: Is NF-kappaB a good target for cancer therapy? Hopes and pitfalls. Nat Rev Drug Discov 8: 33-40, 2009. 